\title{
Staphylococcus ENTEROTOXIGÊNICOS EM LEITE E PRODUTOS LÁCTEOS, SUAS ENTEROTOXINAS E GENES ASSOCIADOS: REVISÃO
}

\author{
MARIA DE FÁTIMA BORGES* \\ EDNA FROEDER ARCURI** \\ JOSÉ LUIZ PEREIRA*** \\ TEREZINHA FEITOSA ${ }^{\star \star \star *}$ \\ ARNALDO YOSHITERU KUAYE ${ }^{\star \star \star \star *}$
}

\begin{abstract}
Esta revisão de literatura teve como objetivo relatar estudos sobre a ocorrência de Staphylococcus enterotoxigênicos e suas enterotoxinas em leite e produtos lácteos, surtos e casos esporádicos de intoxicação, tipos de enterotoxinas estafilocócicas e seus genes codificadores. Dentre o gênero Staphylococcus, S. aureus é a espécie contaminante de maior prevalência em leite e queijos, principalmente queijos artesanais e está freqüentemente associada com surtos de intoxicação alimentar. As vias de contaminação de queijos podem ser o leite, o manipulador e o ambiente de processamento. Causa relevante de contaminação do leite cru é a mastite bovina, que tem $S$. aureus como o principal agente etiológico. Já foram identificados 18 tipos de enterotoxinas $(A, B$, $\mathrm{C}_{1,2,3}, \mathrm{D}, \mathrm{E}, \mathrm{G}, \mathrm{H}, \mathrm{I}, \mathrm{J}, \mathrm{K}, \mathrm{L}, \mathrm{M}, \mathrm{N}, \mathrm{O}, \mathrm{P}, \mathrm{Q}, \mathrm{R}$ e U) e descritos seus respectivos genes. Relatos de ocorrência de cepas coagulase negativa com potencial enterotoxigênico em leite e produtos lácteos indicam a necessidade de reavaliação dos padrões microbiológicos estabelecidos pela legislação brasileira.
\end{abstract}

PALAVRAS-CHAVE: Staphylococcus; ENTEROTOXINAS; LEITE; QUEIJO.

* Pesquisadora, doutora em Tecnologia de Alimentos, Embrapa Agroindústria Tropical, Fortaleza, CE (email: fatima@cnpat.embrapa.br).

** Pesquisadora, doutora em Ciência de Alimentos, Embrapa Gado de Leite, Juiz de Fora, MG (e-mail: edna@cnpgl.embrapa.br).

*** Professor, doutor em Ciência de Alimentos, Departamento de Ciências de Alimentos, Faculdade de Engenharia de Alimentos (FEA), Universidade Estadual de Campinas (UNICAMP), Campinas, SP (email: pereira@fea.unicamp.br).

**** Pesquisadora, doutora em Bioquímica, Embrapa Agroindústria Tropical, Fortaleza, CE (e-mail: tele@cnpat.embrapa.br).

***** Professor, Doutor em Ciência de Alimentos, Departamento de Tecnologia de Alimentos, FEA/UNICAMP, Campinas, SP (e-mail: kuaye@fea.unicamp.br). 


\section{INTRODUÇÃO}

A contaminação dos alimentos por Staphylococcus enterotoxigênicos coagulase positiva e negativa representa problema de saúde pública, devido ao risco de causar intoxicação alimentar (MARTIN, MYERS e LANDOLO, 2001). A intoxicação estafilocócica constitui a causa mais freqüente de surtos de doenças transmitidas por alimentos (DTA) em muitos países e ocorre após a ingestão de alimentos contendo enterotoxinas. Os sintomas dessa enfermidade incluem náuseas, vômitos, dor abdominal e diarréia. Dor de cabeça e queda da pressão arterial, também podem ocorrer. Algumas cepas de espécies desse gênero, quando presentes em populações elevadas (>105 $\mathrm{UFC} / \mathrm{mL}$ ou g) e sob condições adequadas (temperatura, $\mathrm{pH}$, atividade de água e $\mathrm{O}_{2}$ ) produzem uma ou mais enterotoxinas estafilocócicas (SE) nos alimentos (DINGES, ORWIN e SCHLIEVERT, 2000; JABLONSKI e BOHACH, 2001). Já foram descritos 18 tipos de enterotoxinas distintas (Tabela 1). Os tipos clássicos SEA, SEB, SEC ${ }_{1},{ }_{2},{ }_{3}$, SED E SEE são considerados os de maior ocorrência (DINGES, ORWIN e SCHLIEVERT, 2000; MARTIN, MYERS e LANDOLO, 2001).

\section{TABELA 1 - TIPOS DE ENTEROTOXINAS ESTAFILOCÓCICAS (SE) E GENES CODIFICADORES}

\begin{tabular}{|c|c|c|}
\hline $\begin{array}{l}\text { Tipos de } \\
\text { SE }\end{array}$ & $\begin{array}{c}\text { Genes } \\
\text { codificadores }\end{array}$ & Referência \\
\hline SEA & sea & BETLEY e MEKALANOS (1988); BECKER, ROTH e PETERS (1998) \\
\hline SEB & seb & $\begin{array}{l}\text { BERGDOLL, SURGALA e DARK (1959); JONES e KHAN (1986); } \\
\text { BECKER, ROTH e PETERS (1998) }\end{array}$ \\
\hline $\mathrm{SEC}_{1}$ & $\sec _{1}$ & $\begin{array}{l}\text { BORJA e BERGDOLL (1967); BOHACH e SCHIEVERT (1987); } \\
\text { BECKER, ROTH e PETERS (1998) }\end{array}$ \\
\hline $\mathrm{SEC}_{2}$ & $\mathrm{sec}_{2}$ & BERGDOLL, BORJA e AVENA (1965); AVENA e BERGDOLL (1967); \\
\hline $\mathrm{SEC}_{3}$ & $\mathrm{sec}_{3}$ & REISER et al. (1984) \\
\hline SED & sed & $\begin{array}{l}\text { CASMAN et al. (1967); BAYLES e IANDOLO (1989); BECKER, ROTH } \\
\text { e PETERS (1998) }\end{array}$ \\
\hline SEE & see & $\begin{array}{l}\text { BERGDOLL et al. (1971); COUCH, SOLTIS e BETLEY (1988); } \\
\text { BECKER, ROTH e PETERS (1998) }\end{array}$ \\
\hline SEG & seg & $\begin{array}{l}\text { BETLEY, BORST e RESGASSA (1992); MUNSON et al. (1998); } \\
\text { OMOE et al. (2002) }\end{array}$ \\
\hline SEGV & $\operatorname{seg}_{v}$ & BLAIOTTA et al. (2004) \\
\hline SEH & seh & REN et al. (1994); SU e WONG (1995); OMOE et al. (2002) \\
\hline SEI & sei & MUNSON et al. (1998); OMOE et al. (2002) \\
\hline SEIV & $\mathrm{sei}_{v}$ & BLAIOTTA et al. (2004) \\
\hline SEJ & sej & ZHANG, IANDOLO e STEWART (1998); OMOE et al. (2005) \\
\hline SEK & sek & ORWIN et al. (2001); OMOE et al. (2005) \\
\hline SEL & sel & FITZGERALD et al. (2001); OMOE et al. (2005) \\
\hline SEM & sem & JARRAUD et al. (2001); OMOE et al. (2005) \\
\hline SEN & sen & JARRAUD et al. (2001); ORWIN et al. (2003); OMOE et al. (2005) \\
\hline SENv & $\operatorname{sen}_{v}$ & BLAIOTTA et al. (2004) \\
\hline SEO & seo & JARRAUD et al. (2001); OMOE et al. (2005) \\
\hline SEP & sep & OMOE et al. (2005) \\
\hline SEQ & seq & YARWOOD et al. (2002); Omoe et al. (2005) \\
\hline SER & ser & OMOE et al. (2003); Omoe et al. (2005) \\
\hline SEU & seu & LETERTRE et al. (2003) \\
\hline SEUV & $\operatorname{seu}_{v}$ & BLAIOTTA et al. (2004) \\
\hline
\end{tabular}


Entre os alimentos envolvidos em surtos e casos de intoxicação estafilocócica destacam-se o leite cru, o leite pasteurizado e os queijos como os produtos lácteos mais incriminados, sendo $S$. aureus o microrganismo mais freqüente nas investigações epidemiológicas (DE BUYSER et al., 2001; LE LOIR, BARON e GAUTIER, 2003; IKEDA et al., 2005).

O objetivo desta revisão de literatura foi relatar as pesquisas realizadas sobre a contaminação de leite e produtos lácteos por Staphylococcus enterotoxigênicos, a ocorrência de surtos e casos esporádicos de intoxicação estafilocócica e tipos de enterotoxinas e seus genes codificadores.

\section{INTOXICAÇÃO ESTAFILOCÓCICA}

A intoxicação estafilocócica é causada pela ingestão de alimentos contendo enterotoxinas produzidas por Staphylococcus enterotoxigênicos, como S. aureus (com maior prevalência), S. hyicus, S. intermedius, entre outras espécies. Tal intoxicação constitui um dos tipos mais comuns de DTA (LE LOIR, BARON e GAUTIER, 2003).

A intoxicação causada por $S$. aureus manifesta-se logo após a ingestão do alimento contaminado com enterotoxinas pré-formadas. A quantidade de enterotoxina necessária para causar a doença ainda não está bem estabelecida, mas sabe-se que depende da susceptibilidade do indivíduo, do peso corporal e, especialmente, do estado de saúde da pessoa acometida (JABLONSKI e BOHACH, 2001). Para a formação de enterotoxinas em quantidade suficiente para provocar intoxicação são necessárias $10^{5}$ a $10^{6}$ células de S. aureus por grama de alimento (JABLONSKI e BOHACH, 2001). O crescimento de S. aureus e a produção de enterotoxinas são afetados por parâmetros físicos e químicos, como temperatura, pH, atividade de água (Aa), concentração de sal ( $\mathrm{NaCl}$ ) e disponibilidade de oxigênio (Tabela 2).

\section{TABELA 2 - PARÂMETROS IMPORTANTES PARA O DESENVOLVIMENTO DE S. aureus E PRODUÇÃO DE ENTEROTOXINAS EM ALIMENTOS}

\begin{tabular}{ccccc}
\hline \multirow{2}{*}{ Parâmetro } & \multicolumn{2}{c}{ Desenvolvimento } & \multicolumn{2}{c}{ Produção de enterotoxinas } \\
\cline { 2 - 5 } & Ótimo & Variação & Ótima & Variação \\
\hline Temperatura $\left({ }^{\circ} \mathrm{C}\right)$ & $35-37$ & $7-48$ & $35-40$ & $1-45$ \\
$\mathrm{pH}$ & $6,0-7,0$ & $4,0-10,0$ & $6,0-7,0$ & $4,8-9,0$ \\
$\mathrm{Aa}$ & $>0,99$ & $0,83-0,99$ & 0,99 & $? 0,83-0,99$ \\
$\mathrm{NaCl}(\%)$ & $0-4$ & $0-20$ & $0-0,5$ & $0-10$ \\
Atmosfera & Aeróbica & Aeróbica & Aeróbica & Aeróbica Anaeróbica \\
& & Anaeróbica & $\left(5-20 \%\right.$ de $\left.\mathrm{O}_{2}\right)$ & \\
\hline
\end{tabular}

Fonte: ICMSF (1996) (Adaptada).

A doença tem início repentino e severo, normalmente com náusea, vômitos e cólicas, prostração, hipotensão e hipotermia (DINGES, ORWIN e SCHLIEVERT, 2000; BALABAN e RASOOLY, 2000; LE LOIR, BARON e GAUTIER, 2003). Entretanto, a intensidade dos sintomas pode variar de acordo com o grau de suscetibilidade do indivíduo, com a concentração da enterotoxina presente no alimento e a quantidade de alimento ingerida. A recuperação ocorre em torno de dois dias, podendo em alguns 
casos levar mais tempo ou exigir hospitalização (JABLONSKI e BOHACH, 2001). O período de incubação oscila entre 30 minutos e 8 horas, porém os sintomas aparecem entre 2 e 4 horas após a ingestão do alimento contaminado na maioria dos casos (BANNERMAN, 2003).

Na intoxicação estafilocócica, as enterotoxinas agem no trato gastrintestinal. A ação emética, sintoma observado com maior freqüência na intoxicação estafilocócica, parece ter sítios localizados no intestino. O estímulo, transferido pelo nervo vago ao centro do vômito, induz a retroperistalsia do estômago e do intestino delgado, provocando vômitos intensivos (BALABAN e RASOOLY, 2000; DINGES, ORWIN e SCHLIEVERT, 2000). A ação diarréica constitui o segundo sintoma mais comum na intoxicação. Embora seu mecanismo de ação ainda não esteja bem esclarecido, causa inflamação e irritação da mucosa do estômago e intestino delgado (DINGES, ORWIN e SCHLIEVERT, 2000).

A intoxicação estafilocócica, na maioria dos casos, não é notificada aos órgãos de Vigilância Sanitária, o que leva à subnotificação da doença no Brasil e em outros países. Trata-se de doença de curso rápido (24-48 horas) e os indivíduos afetados, geralmente, não necessitam de atendimento médico.

\section{Staphylococcus ENTEROTOXIGÊNICOS}

Entre as espécies de Staphylococcus enterotoxigênicos coagulase positiva, S. aureus está mais relacionado com casos e surtos de intoxicação alimentar pela habilidade de produzirem exotoxinas superantigênicas (PTSAg), como as enterotoxinas que estimulam a proliferação não-específica de células T (DINGES, ORWIN e SCHLIEVERT, 2000). Outras espécies produtoras de coagulase, como S. intermedius (BECKER, ROTH e PETERS 1998) e S. hyicus (ADESIYUN, TATINI e HOOVER, 1984), também produzem enterotoxinas e estão envolvidas em alguns surtos (KHAMBATY, BENNET e SHAH, 1994).

A produção de enterotoxinas por Staphylococcus coagulase negativa (Tabela 3) tem sido relatada em vários estudos, sendo a maioria sob condições de laboratório (VALLE et al., 1990; VERNOZYROZAND et al., 1996a; CHENG-CHUN e LI-FEN, 1997). Os resultados de alguns desses estudos sugerem que Staphylococcus coagulase negativa (RODRIGUEZ et al., 1996; VERNOZY-ROZAND et al., 1996b) podem ser potenciais causadores de intoxicação alimentar. Já foram relatados três surtos de intoxicação estafilocócica associados com espécies coagulase negativa (OMORI e KATO, 1959; BRECKINRIDGE e BERGDOLL, 1971; CARMO et al., 2002b; VERAS et al., 2003).

TABELA 3 - Staphylococcus ENTEROTOXIGÊNICO COAGULASE NEGATIVA

\begin{tabular}{l|l}
\hline \multicolumn{1}{c|}{ Espécie } & \multicolumn{1}{c}{ Referência } \\
\hline S. capitis & VERNOZY-ROZAND et al., 1996b \\
\hline S. conhnii subsp cohnii & $\begin{array}{l}\text { VALLE et al., 1990; RODRIGUEZ et al., 1996; VERNOZY- } \\
\text { ROZAND et al., 1996b }\end{array}$ \\
\hline S. epidermidis & VALLE et al., 1990 \\
\hline S. haemolyticus & VALLE et al., 1990 \\
\hline S. hominis & VALLE et al., 1990; VERNOZY-ROZAND et al., 1996b \\
\hline S. lentus & VALLE et al., 1990; VERNOZY-ROZAND et al., 1996b \\
\hline S. saprophyticus & VALLE et al., 1990; VERNOZY-ROZAND et al., 1996b \\
\hline S. sciuri & VALLE et al., 1990 \\
\hline S. simulanas & VERNOZY-ROZAND et al., 1996b \\
\hline S. warneri & VALLE et al., 1990; VERNOZY-ROZAND et al., 1996b \\
\hline S. xylosus & VALLE et al., 1990; RODRIGUEZ et al., 1996; VERNOZY- \\
\hline S. chromogenes & ROZAND et al., 1996b \\
\hline & VALLE et al., 1990 \\
\hline
\end{tabular}




\section{ENTEROTOXINAS ESTAFILOCÓCICAS E GENES CODIFICADORES}

As enterotoxinas estafilocócicas constituem grupo de proteínas extracelulares de cadeia simples, com baixa massa molecular ( 26 a $30 \mathrm{kDa}$ ) e ponto isoelétrico entre 7,0 a 8,6. São ricas em aminoácidos lisina, ácido aspártico, ácido glutâmico e resíduos de tirosina. A maioria apresenta alça de cistina, necessária para sua própria configuração, e a qual está, provavelmente, envolvida na sua atividade emética. São hidrossolúveis e resistentes à ação de enzimas proteolíticas do sistema digestivo, permanecendo ativas após a ingestão (LE LOIR, BARON e GAUTIER, 2003). Sua produção ocorre durante toda fase do crescimento bacteriano, mas principalmente durante a fase exponencial (SORIANO et al., 2002). Outra característica importante envolve a termoestabilidade, pois essas enterotoxinas são capazes de resistir a tratamentos térmicos como a pasteurização e a ultrapasteurização.

As enterotoxinas são nomeadas com as letras do alfabeto de acordo com a ordem cronológica de suas descobertas. Já foram descritos 18 tipos de enterotoxinas distintas (Tabela 1), as quais compartilham similaridade na estrutura e seqüência (BALABAN e RASOOLY, 2000; LE LOIR, BARON e GAUTIER, 2003). Com base nas características antigênicas são reconhecidos oito tipos sorológicos de enterotoxinas: SEA, SEB, SEC, SED, SEE (DINGES, ORWIN e SCHLIEVERT, 2000), SEH (REN et al. 1994; SU e WONG, 1995; OMOE et al. 2002), SEG e SEI (OMOE et al., 2002; JØRGENSEN et al., 2005). Outras 12 enterotoxinas (Tabela 1 ) foram identificadas e caracterizadas nos últimos anos (OMOE et al., 2005).

O seqüenciamento parcial dos aminoácidos das enterotoxinas SEA, SEB e SEC evidenciou a existência de região homóloga nas três moléculas, sugerindo que essa região seja o sítio ativo da molécula de enterotoxina (DINGES, ORWIN e SCHLIEVERT, 2000; JABLONSKI e BOHACH, 2001). Embora sejam similares em sua composição e atividade biológica, as enterotoxinas são identificadas separadamente em função de diferenças antigênicas. Várias enterotoxinas sorologicamente distintas têm sido reconhecidas e classificadas de SEA até SEU e seus genes de sea até seu. Inicialmente, a toxina da Síndrome do Choque Tóxico foi equivocadamente identificada como SEF e por isso não existe a enterotoxina sorotipo $F$. Pequenas variações antigênicas da $S_{E C} C_{1,2,3}$ têm sido descritas (AVENA e BERGDOLL, 1967; REISER et al., 1984; BECKER, ROHT e PETERS, 1998), assim como duas SEH distintas (OMOE et al., 2002). Normalmente, isto ocorre em cepas que secretam mais de um tipo de enterotoxinas (OMOE et al., 2005).

As enterotoxinas estafilocócicas são codificadas por genes presentes em bacteriófago (SEA, SED, SEE e SEJ), plasmídios (SEH e SEP), cromossomo (SEH e SEP) e ilhas de patogenicidade cromossomal, a exemplo de SEB, SEC, SEG, SEGV, SEI, SEI, SEM, SEN, SEO, SEK, SEL e SEQ (BAYLES e IANDOLO, 1989; SU e WONG, 1995; MUNSON et al., 1998; JARRAUD et al., 2001; OMOE et al., 2002; BLAIOTTA et al., 2004).

A relação entre as novas enterotoxinas e a intoxicação estafilocócica ainda não está completamente elucidada. Há poucos relatos na literatura sobre a ocorrência dos genes que codificam essas novas enterotoxinas, envolvendo principalmente amostras clínicas ou de coleções bacterianas (JARRAUD et al., 1999; ABE et al., 2000; JARRAUD et al., 2001; OMOE et al., 2002). Pouco foi relatado sobre a detecção das novas enterotoxinas em cepas de Staphylococcus, principalmente $S$. aureus, isolados de alimentos (MCLAUCHLIN et al., 2000; AKINEDEN et al., 2001; ROSEC e GIGAUD, 2002; BLAIOTTA et al., 2004; JØRGENSEN et al., 2005). Por outro lado, os relatos sobre a ocorrência das enterotoxinas clássicas (SEA, SEB, SEC ${ }_{1,2,3}$, SED e SEE) em alimentos são numerosos (DE LUCA, ZANETTI e STAMPI, 1997; ROSEC et al., 1997; MEYRAND e VERNOZY-ROZAND 1999; MCLAUCHLIN et al., 2000; AKINEDEN et al., 2001; ROSEC e GIGAUD, 2002; CHAPAVAL, 2003).

Para avaliar o papel das novas enterotoxinas na intoxicação alimentar estafilocócica é necessário o desenvolvimento de testes imunológicos para a detecção das mesmas em alimentos. Por enquanto, só há kits imunológicos disponíveis comercialmente para detecção das enterotoxinas 
clássicas (SEA a SEE). Os principais métodos rápidos, disponíveis no mercado para detecção de enterotoxinas estafilocócicas em fluidos sobrenadantes de culturas de Staphylococcus spp. e em extratos de alimentos, são kits imunoenzimáticos que em sua maioria utiliza Enzyme-Linked Immunosorbent Assay (ELISA); Latex Agglutination (LA); Reversed Passive Latex agglutination (RPLA) e Enzyme linked Fluorescent Assay (ELFA) (PIMBLEY; PATEL, 1998). Entre os principais kits incluemse: SET-RPLA (Oxoid); BOMMELI SET-EIA (Dr. Bommeli AG); TECRA SET-VIA (Bio-Enterprises Pty Ltd); RIDASCREEN SET (R-Biopharm GmbH); TRANSIA (Transia Dffchamb - SA) e o VIDAS ${ }^{\circledR}$ Staph enterotoxin - SET (BioMérieux SA, Marcy-l'Etoile, France) (BRETT, 1998).

O gene femA tem sido explorado como marcador específico de $S$. aureus em testes baseados em pesquisa de DNA. Esse gene codifica fator essencial para a resistência a meticilina e está universalmente presente em todas as cepas de $S$. aureus (MEHROTA, WANG e JOHNSON, 2000). A amplificação do gene femA ou parte dele por PCR constitui ferramenta útil na diferenciação de espécies de Staphylococcus, sendo portanto alternativa rápida e segura para identificação dessa bactéria (MEHROTRA, WANG e JOHNSON, 2000; ARCURI et al. 2004; FREITAS, 2005).

A multiplex PCR consiste na amplificação simultânea de vários genes pelo uso de múltiplos pares de primers na mesma reação. Vários testes multiplex PCR têm sido desenvolvidos para detecção de genes codificadores de enterotoxinas estafilocócicas (VERNOZY-ROZAND et al., 1996b; BECKER, ROTH e PETERS, 1998; MEHROTA, WANG e JOHNSON, 2000). MONDAY e BONACH (1999) desenvolveram teste de multiplex PCR para detecção dos genes das toxinas SEA a SEJ. DODD, SHARMA e REES (2000) desenvolveram teste multiplex PCR de reação única para genes das enterotoxinas de $S$. aureus com primer universal de genes de toxinas em combinação com primers toxina-específicos para amplificar produtos característicos de genes de toxinas estafilocócicas.

\section{OCORRÊNCIA DE Staphylococcus ENTEROTOXIGÊNICO E DE ENTEROTOXINAS EM LEITE E PRODUTOS LÁCTEOS}

A presença de Staphylococcus enterotoxigênicos e suas enterotoxinas têm sido constatada com freqüência em leite cru e queijo (ROSEC e GIGAUD, 2002; SENA, 2000; LAMAITA et al., 2005; LE LOIR, BARON e GAUTIER, 2003). O leite cru obtido de animais com infecção estafilocócica nas glândulas mamárias (mastite) tem sido considerado a principal fonte de cepas S. aureus.

Na Califórnia, CENCI-GOGA et al. (2003) avaliaram o potencial enterotoxigênico de 160 cepas de $S$. aureus isoladas de leite proveniente de vacas com mastite. Constataram que 22 cepas eram produtoras de enterotoxinas e dentre essas, sete produziram SEC, doze SED e três SEC e SED.

Na Alemanha, AKINEDEN et al. (2001) identificaram, em cepas de $S$. aureus isoladas de leite proveniente de vacas com mastite de oito fazendas de diferentes municípios, a presença de genes que codificam as enterotoxinas SEA, SEC, SED, SEG, SEI e SEJ.

Na Itália, DE LUCA, ZANETTI e STAMPI (1997) avaliaram a presença S. aureus em quatro tipos de queijos comercializados em Bologna e verificaram que 16,3\% (22/135) das amostras estavam contaminadas com o patógeno. Em outro trabalho, NORMANNO et al. (2005) analisaram leite cru e pasteurizado e outros derivados (queijo, coalhada, ricota, sorvetes, etc.). Isolaram 362 cepas de $S$. aureus, das quais 217 produziram SEA $(26,7 \%)$, SEB $(0,9 \%)$, SEC $(28,1 \%)$, SED $(15,7 \%)$, SEA e SEB (1,8\%), SEA e SED (26,0\%), SEA e SEC (0,5\%) e SEC e SED $(0,5 \%)$.

$\mathrm{Na}$ França, ROSEC et al. (1997) isolaram 213 cepas de S. aureus em 121 produtos alimentícios, incluindo leite e queijos, e constataram que $30,5 \%$ (65/213) das cepas produziam pelo menos uma ou duas das cinco enterotoxinas clássicas. Em outra pesquisa, ROSEC e GIGAUD (2002) avaliaram 332 isolados dessa bactéria provenientes de vários alimentos produzidos naquele país. Constataram elevada freqüência (57\%) de cepas que apresentavam genes que codificam enterotoxinas (SEG, SEH, CEI e 
SEJ), além de genes das enterotoxinas clássicas.

Na Eslováquia, HOLECKOVÁ et al. (2002) observaram alta percentagem de cepas de S. aureus enterotoxigênicos em queijo de leite de ovelha. Das 19 cepas isoladas, nove produziram enterotoxinas com prevalência de SEB.

A ocorrência de altas contagens de Staphylococcus coagulase positiva e S. aureus em queijo de coalho, produzido em vários estados do Nordeste (Alagoas, Bahia, Ceará, Paraíba, Pernambuco e Rio Grande do Norte), tem sido relatada em muitos estudos (MENDES et al., 1999; PAIVAe CARDONHA, 1999; RAPINI et al., 2002; FEITOSA et al., 2003; BORGES et al., 2003). Na maioria desses estudos, os queijos foram classificados como impróprios para o consumo humano devido níveis de contaminação superiores aos permitidos na legislação (103 UFC/g) brasileira (ANVISA, 2001).

No Ceará, destacam-se os trabalhos de HILUY e ARAÚJO (1999), BORGES et al. (2003), LIMA (2005), BRUNO et al. (2005) que ao investigarem amostras de queijo de coalho constataram índices de 96\% (24/25), 91\% (39/43), 54\% (43/80) e 50\% (4/8), respectivamente, de amostras em desacordo com a legislação $\left(10^{3} \mathrm{UFC} / \mathrm{g}\right)$ para os valores de estafilococos coagulase positiva.

No Rio Grande do Norte, os trabalhos de PAIVA e CARDONHA (1999) e FEITOSA et al. (2003) revelaram percentagens de $30 \%$ (6/20) e 72,7\% (8/11) respectivamente de amostras de queijos de coalho acima dos padrões legais para Staphylococcus coagulase positiva.

Em Recife (PE), MENDES et al. (1999) avaliaram 105 amostras de queijo de coalho procedentes de 15 municípios e comercializadas na cidade. Verificaram que todos os municípios apresentavam amostras de queijos acima dos padrões legais para estafilococos, em porcentagem que variou de $13 \%$ a 90\%. CUNHA NETO, SILVA e STANFORD (2002) isolaram Staphylococcus enterotoxigênicos em queijo de coalho e $100 \%$ dessas cepas foram positivas para enterotoxinas estafilocócicas clássicas. SENA (2000) analisou 90 amostras de queijo de coalho e isolou 377 cepas de Staphylococcus, assim distribuídas: 218 (57,8\%) de S. aureus, 96 (25.5\%) de S. epidermidis, $41(10,9 \%)$ de S. hyicus e 22 $(5,8 \%)$ de $S$. intermedius. Pools de cepas foram testados quanto ao potencial de produção de enterotoxinas por indução sob condições laboratoriais, sendo observado que dos 78 pools de cepas de S. aureus, 48 (61,5\%) produziram SEB; 10 (12,5\%) SEC e 2 (2,5\%) SED. Dos 11 pools de S. intermedius, $7(63,6 \%)$ produziram SEB e os pools de $S$. epidermidis e de $S$. hyicus não produziram enterotoxinas.

Na avaliação de queijo de coalho comercializado nas praias de Salvador e Maceió, RAPINI et al. (2002) observaram que $100 \%$ das amostras estavam contaminadas por Staphylococcus sp. e por enterotoxinas SEB e SEC.

PERSI (2001), em São José do Rio Preto (SP), verificou que 23,3\% (7/30) amostras de queijo Minas frescal artesanal e 96,7\% (23/30) industrial apresentavam-se em desacordo com os padrões legais devido às altas contagens de coliformes fecais ou Staphylococcus coagulase positiva. Em Campinas, CARVALHO, VIOTTO e KUAYE (2007) avaliaram o nível de contaminação de queijo Minas frescal por estafilococos coagulase positiva. Constataram que 12,9\% (4/31) e 9,7\% (3/31) dos queijos produzidos pela técnica convencional e por acidificação direta, respectivamente, não atenderam ao padrão legal vigente.

ALMEIDA FILHO e NADER FILHO (2000) mostraram quadro preocupante da baixa qualidade microbiológica de queijos Minas frescal artesanais comercializados em Poços de Caldas, (MG). Verificaram que 50\% (40/80) das amostras apresentavam-se com valores de S. aureus acima de $10^{5} \mathrm{UFC} / \mathrm{g}$, valor indicativo da produção de enterotoxinas.

NICOLAU et al. (2001) avaliaram amostras de queijo mussarela da região de Goiânia (GO) e verificaram a presença de $S$. aureus em 58,2\% (127/218) das amostras. De 132 cepas analisadas, 9,8\% (13/132) apresentaram potencial para produção de enterotoxinas e dessas, 13 cepas (61,5\%) produziram SEA, $23,1 \%$ SEB, $7,7 \%$ SEC e $7,7 \%$ SEA e SEB. Nos extratos de queijo a presença de enterotoxinas foi detectada diretamente em 9,2\% (7/76) das amostras, sendo que $71,5 \%$ (5) eram SEA e $28,5 \%$ (2) SEB. 
LAMAITA et al. (2005) observaram a produção de enterotoxinas (SEA, SEB, SEC e SED) em cepas de Staphylococcus coagulase positiva e negativa isoladas de amostras de leite cru refrigerado, oriundo de diferentes propriedades rurais localizadas na região Sudeste. Verificaram maior freqüência de SEC e SEB, seguidas de SED e SEA. Também constataram maior percentual de cepas produtoras de enterotoxinas coagulase negativa, fato preocupante uma vez que esses microrganismos não são contemplados pela legislação vigente no Brasil.

\section{SURTOS DE INTOXICAÇÃO ESTAFILOCÓCICA ASSOCIADOS AO CONSUMO DE LEITE E PRODUTOS LÁCTEOS}

Surtos e casos esporádicos de intoxicação estafilocócica atribuída ao consumo de produtos lácteos, principalmente queijos, têm sido relatados em vários países (SABIONI, NASCIMENTO e PEREIRA, 1994; ALTEKRUSE, et al., 1998; MEYRAND e VERNOZY-ROZAND, 1999; DE BUYSER et al., 2001; LECLERC et al., 2002; CARMO et al., 2002). A contaminação de queijos é atribuída principalmente à utilização de leite cru na sua fabricação, ou a falhas durante o processamento, principalmente na pasteurização, manipulação após o processamento, ou na distribuição do produto.

Nos Estados Unidos, no período de 1993-1997, S. aureus foi envolvido em 42 surtos de intoxicação alimentar com 1.413 casos notificados e um óbito (OLSEN et al., 2000). Leite e queijos estavam entre os alimentos implicados. A intoxicação estafilocócica representa cerca de 4,0\% das doenças de origem alimentar bacteriana, sendo responsável por 1.753 hospitalizações e duas mortes a cada ano (USDA, 2006).

$\mathrm{Na}$ Europa, surtos de intoxicações estafilocócicas foram monitorados em vários países no período de 1993-1998. Os produtos lácteos foram responsáveis por 3,9\% dos surtos na Alemanha, 6,7\% na Noruega, 5,4\% na Bélgica, 9,1\% na Escócia, 1,6\% na Espanha, 26\% na França, 3,0\% na Inglaterra e País de Gales, 3,6\% na Itália; 5,0\% na Holanda, 1,7\% em Portugal e 1,7\% na Suécia (FAO/WHO, 2002).

No Japão, entre 1987-1996, ocorreram 32 casos de doenças de origem alimentar atribuídos a S. aureus, em escolas e berçários escolares, afetando 2.846 crianças (MICHINO e OTSUKI, 2000). Em julho de 2000 houve outro surto de intoxicação atribuído ao consumo de iogurte contaminado com enterotoxina A, envolvendo 13.420 notificações (NIID, 2001).

Segundo registros do Sistema de Informação para a Vigilância das Enfermidades Transmitidas por Alimentos na América Latina e Caribe (SIRVETA), entre 1993 e 2002, ocorreram 250 surtos de intoxicação estafilocócica envolvendo produtos lácteos com acometimento de 4.247 pessoas em 11 países dessa região. Há 16 relatos de surtos causados por queijos ocorridos no Brasil, com 86 pessoas acometidas (Tabela 4). Dois desses surtos foram notificados no estado do Ceará no ano de 2000 , atribuídos ao consumo de queijos e envolvendo 14 pessoas (INPPAZ/OPS/OMS, 2006).

No mundo, assim como no Brasil, o número de surtos e casos esporádicos de intoxicações estafilocócicas são superiores aos reportados pela Vigilância Sanitária. Muitos casos não são notificados ou investigados devido, principalmente, ao rápido curso da doença. No Brasil, entre 1999 e 2004 foram notificados 3.064 surtos de DTA à Secretaria de Vigilância em Saúde (SVS), com acometimento de 57.353 pessoas e registro de 37 óbitos. S. aureus foi identificado em $18,1 \%$ dos casos, ocupando a segunda posição entre os agentes etiológicos identificados (CARMO et al., 2005).

No Brasil, os surtos de DTA investigados envolvendo produtos lácteos têm sido associados principalmente ao consumo de queijos do tipo Minas frescal, Minas padrão e de queijo de coalho. SABIONI, HIROOKA e SOUZA (1988) investigaram um surto devido a queijo Minas frescal contaminado por S. aureus em Ouro Preto (MG), em julho de 1987. O nível de contaminação no queijo foi de 9,3 $\times 10^{7} \mathrm{UFC} / \mathrm{g}$ e as cepas isoladas eram produtoras de enterotoxinas SEA, SEB, SED e SEE. Nessa mesma cidade, em janeiro de 1992, outro surto de intoxicação estafilocócica foi atribuído ao consumo de queijo Minas. S. aureus foi o agente etiológico e o nível de contaminação 
variou de $7,0 \times 10^{5}$ a 2,1 $\times 10^{8} \mathrm{UFC} / \mathrm{g}$. Além disso, 93,7\% das cepas eram produtoras de enterotoxinas SEA, SEB ou SED (SABIONI, NASCIMENTO e PEREIRA, 1994). Em 1996 ocorreu outro surto, atribuído a esse mesmo tipo de queijo, envolvendo sete pessoas da mesma família e $S$. aureus foi o agente etiológico identificado. A população do patógeno nos queijos foi de $2,9 \times 10^{8} \mathrm{UFC} / \mathrm{g}$, sendo detectadas cepas de $S$. aureus produtoras de enterotoxina SED. No queijo foi detectado $180 \mathrm{ng} / \mathrm{mL}$ de enterotoxina SEH (PEREIRA et al.,1996).

\section{TABELA 4 - RELATOS DE SURTOS DE INTOXICAÇÃO ESTAFILOCÓCICA ATRIBUÍDOS AO CONSUMO DE PRODUTOS LÁCTEOS NO BRASIL, PERÍODO DE 1993-2002}

\begin{tabular}{cccc}
\hline Local & Veículo & $\begin{array}{c}\text { Agente } \\
\text { etiológico }\end{array}$ & $\begin{array}{c}\text { No de pessoas } \\
\text { envolvidas }\end{array}$ \\
\hline Belo Horizonte - MG & Queijo & S. aureus & 3 \\
Belo Horizonte - MG & Queijo & S. aureus & 8 \\
Belo Horizonte - MG & Queijo & S. aureus & 3 \\
Arapongas - PR & Queijo colonial & S. aureus & 7 \\
Curitiba - PR & Queijo & S. aureus & 3 \\
Curitiba - PR & Queijo & S. aureus & 4 \\
Curitiba - PR & Queijo & S. aureus & 4 \\
P. Fontim - PR & Queijo & S. aureus & 5 \\
Viamão - RS & Queijo & S. aureus & 4 \\
Rio Grande - RS & Queijo & S. aureus & 12 \\
Caxias do Sul - RS & Queijo & S. aureus & 8 \\
Quedas do Iguaçu - PR & Queijo colonial & S. aureus & 4 \\
Itapajé - CE & Queijo & S. aureus & 7 \\
Porto Alegre - RS & Queijo colonial & S. aureus & 3 \\
Fortaleza - CE & Queijo & S. aureus & 7 \\
Autazes - AM & Queijo & S. aureus & 4 \\
Total & & & 86 \\
& & &
\end{tabular}

Fonte: INPPAZ/OPS/OMS (2006).

No período de 1997 a 2002, vários surtos de intoxicação alimentar ocorridos em Minas Gerais foram investigados pela Fundação Ezequiel Dias (FUNED). Leite e produtos derivados (queijos canastra, Minas, mussarela e ralado, requeijão e bebida láctea) foram envolvidos em muitos casos. As contagens de Staphylococcus sp. nos produtos incriminados variaram de 6,0 $\mathrm{x}$ $10^{3}$ a $1,8 \times 10^{8} \mathrm{UFC} / \mathrm{g}$ e as principais enterotoxinas estafilocócicas envolvidas nos surtos foram SEA, SEB e SEC (VERAS et al. 2003). Conforme relatórios da FUNED, no período de 1995 a 2001, alimentos contaminados com enterotoxinas estafilocócicas produzidas por S. aureus causaram 112 surtos com o envolvimento de 12.820 pessoas e 17 mortes. Diversos tipos de queijos foram responsáveis por 23 desses surtos, com 600 pessoas acometidas e um óbito (CARMO, 2002a).

CARMO et al. (2002b) relataram a ocorrência de dois surtos de intoxicação estafilocócica causados pelo consumo de queijo Minas e leite, ocorridos em Manhuaçu e Passa Quatro (MG). No primeiro surto, o consumo de queijo Minas foi incriminado e envolveu 50 pessoas. As amostras de queijo e de leite cru inicial apresentaram contagens de $S$. aureus de $2,4 \times 10^{3}$ a 2,0 $\times 10^{8} \mathrm{UFC} / \mathrm{g}$ e 
presença de enterotoxinas SEA, SEB e SEC. No segundo surto, o consumo de leite cru proveniente de animais com mastite (contagem de estafilococos coagulase negativa superior a 2,0 $\times 10^{8} \mathrm{UFC} / \mathrm{mL}$ e presença de enterotoxinas SEC e SED) causou a intoxicação de 328 pessoas.

O Núcleo de Epidemiologia da Secretária de Saúde do Estado do Ceará, no Informe Anual de Surtos de DTA em 2003, notificou cinco surtos de DTA envolvendo 311 pessoas. Um surto foi atribuído ao consumo de queijo Minas frescal e queijo de coalho. Onze pessoas foram acometidas por intoxicação estafilocócica (CEARÁ, 2004).

\section{CONCLUSÃO}

$\mathrm{Na}$ literatura há inúmeros registros de ocorrência de S. aureus e outras espécies de Staphylococcus coagulase positiva em leite e produtos lácteos, principalmente em queijos artesanais (como queijo de coalho, Minas frescal e colonial). Muitas vezes esses tipos de queijos são classificados como impróprios para consumo devido ao elevado nível de contaminação por bactérias patogênicas. Dentre essas, destacam-se S. aureus, coliformes fecais, E. coli, L. monocytogenes e Salmonella. As vias de contaminação de queijos podem ser o leite, o manipulador e o ambiente de processamento. Fonte relevante de contaminação no leite cru é a mastite bovina, que tem S. aureus como o principal agente etiológico. Os estudos realizados nas indústrias revelam que a contaminação cruzada após a pasteurização do leite seria importante fonte de contaminação dos queijos por Staphylococcus enterotoxigênicos. O leite e produtos lácteos, também têm sido associados com freqüência a surtos e casos esporádicos de intoxicação estafilocócica. Relatos de ocorrência de cepas coagulase negativa, com potencial enterotoxigênico em leite e produtos lácteos, indicam a necessidade de reavaliação dos padrões microbiológicos estabelecidos pela legislação brasileira para Staphylococcus enterotoxigênico em alimentos. Tais padrões correlacionam a produção da enzima coagulase com a capacidade de produção de enterotoxinas por Staphylococcus spp.

\section{ABSTRACT \\ ENTEROTOXIGENIC Staphylococcus IN MILK AND DAIRY PRODUCTS, ITS ENTEROTOXINS AND RELATED GENES: A REVIEW}

This review summarizes publications about the occurrence of enterotoxigênic Staphylococcus and its enterotoxins in milk and dairy products, outbreaks and sporadic cases of staphylococcal food poisoning, enterotoxin types and its genes. Among the genus Staphylococcus, S. aureus is the prevalent species in milk and cheeses, mainly homemade cheeses, and is often associated with outbreaks of food poisoning. Cheese can be contaminated by raw milk, the manipulator and, the processing environment. An important source of raw milk contamination is the bovine mastitis, which have $S$. aureus as the most prevalent etiologic agent. 18 types of enterotoxinas $\left(A, B, C_{1,2,3}, D\right.$, and $, G, H, I, J, K, L, M, N, P, Q, R$ and $U$ ) have already been identified and their genes have also been described. Reports of the occurrence of coagulase negative strains with enterotoxigenic potential, in milk and milk products, indicate the necessity of reevaluation of the microbiological standards established by Brazil's legislation.

KEY-WORDS: Staphylococcus; ENTEROTOXINS; OUTBREAKS; MILK; CHEESE.

\section{REFERÊNCIAS}

1 ABE, J.; ITO, Y.; ONIMARU, M.; KOHSAKA, T.; TAKEDA, T. Characterization and distribution of a new enterotoxin-related superantigen produced by Staphylococcus aureus. Microbiology and Immunology, Tokyo, v. 44, n. 2, p. 79-88, Feb. 2000.

2 ADESIYUN, A. A.; TATINI, S. R.; HOOVER, D. G. Productions of enterotoxins by Staphylococcus hyicus. Veterinary Microbiology, Shannon, v. 9, n. 5, p. 487-495, Sept. 1984. 
3 ANVISA. Agência Nacional de Vigilância Sanitária. Aprova regulamento técnico sobre os padrões microbiológicos para alimentos. Resolução RDC n 12, de 02 de janeiro de 2001. Diário Oficial [da] Republica Federativa do Brasil. Brasília, DF, 10 jan. 2001. Disponível em: <http://www.anvisa.gov.br/ legis/resol/12-01rda.htm>. Acesso em: 07 fev. 2006.

4 AKINEDEN, Ö.; ANNEMÜLLER, C.; HASSAN, A. A.; LÄMMLER, C.; WOLTER, W.; ZSCHÖCK, M. Toxin genes and their characteristics of Staphylococcus aureus isolated from milk of cows with mastitis. Clinical and Diagnostic Laboratory Immunology, Washington, v. 8, n. 5, p. 959-964, Sept. 2001.

5 ALMEIDA FILHO, E. S.; NADER FILHO, A. Ocorrência de Staphylococcus aureus em queijo Minas frescal. Revista de Saúde Pública, São Paulo, v. 34, n. 6, p. 578-580, dez. 2000.

6 ALTEKRUSE, S. F.; TIMBO, B. B.; MOWBRAY, J. C.; BEAN, N. H.; POTTER, M. E. Cheese-associated outbreaks of human illness in the United States, 1973 to 1992: sanitary manufacturing practices protect consumers. Journal of Food Protection, Des Moines, v. 61, n. 7, p. 709-725, Oct. 1998.

7 ARCURI, E. F.; OLIVEIRA, R. C.; BRITO, J. R. F.; LANGE, C.; BRITO, M. A. Avaliação do potencial enterotoxigênico de Staphylococcus aureus isolados de leite cru refrigerado pela detecção dos genes sea, seb, sec, e sed através da PCR. In: CONGRESSO BRASILEIRO DE QUALIDADE DO LEITE, 1, 2004, Passo Fundo. Anais... Passo Fundo: Universidade Federal de Passo Fundo, 2004. p. 1-3.

8 AVENA, R. M.; BERGDOLL, M. S. Purification and some physicochemical properties of enterotoxin C, Staphylococcus aureus strain 361. Biochemistry, Columbus, v. 6, n. 6, p. 1474-1480, Jun. 1967.

9 BALABAN, N.; RASOOLY, A. Staphylococcal enterotoxins. International Journal of Food Microbiology, Amsterdam, v. 61, n. 1, p. 1-10, Oct. 2000.

10 BANNERMAN, T. L. Staphylococcus, Micrococcus, and other catalase positive coci that grow aerobically. In: MURRAY, P.R.; BARON, E. J.; JORGENSEN, J. H.; PFALLER, M. A.; YOLKEN, R. H. (Ed.). Manual of clinical microbiology. $8^{\text {th }}$ ed. Washington, D. C.: ASM, 2003. v. 1. p. 384-404.

11 BAYLES, K. W.; IANDOLO, J. Genetic and molecular analyses of the gene encoding staphylococcal enterotoxin D. Journal of Bacteriology, Washington, v. 171, v. 9, p. 4799-4806, Sept. 1989.

12 BECKER, K.; ROTH, R.; PETERS, G. Rapid and specific detection of toxigenic Staphylococcus aureus: use of two multiplex PCR enzyme immunoassays for amplification and hybridization of staphylococcal enterotoxin genes, and toxic shock syndrome toxin 1 gene. Journal of Clinical Microbiology, Washington, v. 36, n. 9, p. 2548-2553, Sept. 1998.

13 BERGDOLL, M. S.; SURGALA, J.; DACK, G. M. Staphylococcal enterotoxin. Identification of a specific precipitating antibody with enterotoxin-neutralizing property. The Journal of Immunology, Bethesda, $v$. 83, n. 3, p. 334-338, Mar. 1959.

14 BERGDOLL, M. S.; BORJA, C. R.; AVENA, R. M. Identification of a new enterotoxin as enterotoxin C. Journal of Bacteriology, Washington, v. 90, n. 5, p. 1481-1485, Nov. 1965.

15 BERGDOLL, M. S.; BORJA, C. R.; ROBBINS, R.; WEISS, K. F. Identification enterotoxin E. Infection and Immunity, Washington, v. 4, n. 5, p. 593-593, Nov. 1971.

16 BETLEY, M. J.; MEKALANOS, J. J. Nucleotide sequence of the type A staphylococcal enterotoxin gene. Journal of Bacteriology, Washington, v. 170, n. 1, p. 34-41, Jan. 1988.

17 BETLEY, M. J.; BORST, D. W.; REGASSA, L. B. Staphylococcal enterotoxin, toxic shock syndrome and staphylococcal pyrogenic enterotoxins: a comparative study of their molecular biology. Chemical and Immunology, New York, v. 55, p. 1-35, n.1, Jan. 1992.

18 BLAIOTTA, G.; ERCOLINE, D.; PENNACCHIA, C.; FUSCO, V.; CASABURI, A.; PEPE, O.; VILLANI, F. PCR detection of staphylococcal enterotoxin genes in Staphylococcus spp. strains isolated from meat and dairy products. Evidence for new variants of seG and seL in S. aureus AB-8802. Journal of Applied Microbiology, Belfast, v. 97, n. 5, p. 719-730, May 2004.

19 BOHACH, G. A.; SCHIEVERT, P. M. Nucleotide sequence of the staphylococcal enterotoxin $\mathrm{C}_{1}$ gene and relatedness to other pyrogenic toxins. Molecular Genetics and Genomics, Berlin, v. 209, n. 1, p. 15-20, Aug. 1987. 
20 BORGES, M. F.; FEITOSA, T.; NASSU, R. T.; MUNIZ, C. R.; AZEVEDO, E. H. F de; FIGUEIREDO, E. A. T. Microrganismos patogênicos em queijo de coalho produzido no Ceará, Brasil. Boletim do CEPPA, Curitiba, v. 21, n. 1, p. 31-40, jan./jun. 2003.

21 BORJA, C. R.; BERGDOLL, M. S. Purification and partial characterization of enterotoxin C produced by Staphylococcus aureus strain 137. Biochemistry, Columbus, v. 6, n. 5, p. 1467-1473, May 1967.

22 BRECKINRIDGE, J. C.; BERGDOLL, M. S. Outbreak of food-borne gastroenteritis due to a coagulasenegative enterotoxin producing Staphylococcus. New England Journal of Medicine, Boston, v. 284, n. 10, p. 541-543, Oct. 1971.

23 BRETT, M. M. Kits for detection of some bacterial food poisoning toxins: problems, pitfalls and benefits. Journal of Applied Microbiology Symposium Supplement, London, v. 84, n. S1, p. 110S-118S, Jul. 1998.

24 BRUNO, L. M.; FEITOSA, T.; NASSU, R. T.; CARVALHO, J. D. G.; ANDRADE, A. A. Avaliação microbiológica de queijos de coalho artesanais e industrializados comercializados em Fortaleza, CE. Revista do Instituto de Laticínios Cândido Tostes, Juiz de Fora, v. 60, n. 345, p. 217-220, jul./ago. 2005.

25 CARMO, G. M. I.; OLIVEIRA, A. A.; DIMECH, C. P.; SANTOS, D. A.; ALMEIDA, M. G.; BERTO, L. H.; ALVES, R. M. S.; CARMO, E. H. Vigilância epidemiológica das doenças transmitidas por alimentos no Brasil, 1999-2004. Boletim Eletrônico Epidemiológico - Secretaria de Vigilância em Saúde, Brasília, v. 5, n. 6, p. 1-7, dez. 2005. Disponível em: http://portal.saude.gov.br/portal/arquivos/pdf/bol_epi_6_2005_corrigido.pdf>. Acesso em: 19 jul. 2006.

26 CARMO, L. S. Intoxicação alimentar. Revista Minas faz Ciências, Belo Horizonte, n. 11, p. 1-2, jun./ago, $2002 a$. Disponível em: <http://revista.fapemig.br/11/index.htlm>. Acesso em: 27 abr. 2006.

27 CARMO, L. S.; DIAS, R. S.; LINARDI, V. R.; SENA, M. J.; SANTOS, D. A.; FARIA, M. E.; PENA, E. C.; JETT, M.; HENEINE, L. G. Food poisoning due to enterotoxigenic strains of Staphylococcus present in Minas cheese and raw milk in Brazil. Food Microbiology, London, v.19, n. 1, p. 9-14, Jan./Feb. 2002.

28 CARVALho, J. D. G.; VIOTTO, W. H.; KUAYE, A. Y. The quality of Minas frescal cheese produced by different technological processes. Food Control, Oxford, v. 18, n. 3, p. 262-267, Mar. 1997.

29 CASMAN, E. P.; BENNETT, R. W.; DORSEY, A. E.; ISSA, J. A. Identification of a fourth staphylococcal enterotoxin, enterotoxin D. Journal of Bacteriology, Washington, v. 94, n. 6, p. 1875-1882, Dec. 1967.

30 CEARÁ. Secretaria da Saúde do Estado do Ceará. Núcleo de Epidemiologia. Célula de Vigilância Epidemiológica. Informe anual de surtos das doenças transmitidas por alimentos. Fortaleza, 2004. 4 p.

31 CENCI-GOGA, B. T.; KARAMA, M.; ROSSITTO, P. V.; MORGANTE, R. A.; CULLOR, J. S. Research note enterotoxin production by Staphylococcus aureus isolated from mastitic cows. Journal of Food Protection, Des Moines, v. 66, n. 9, p. 1693-1696, Sept. 2003.

32 CHAPAVAL, L. Detecção de enterotoxinas estafilocócicas produzidas por Staphylococcus aureus no leite bovino por eletroforese capilar e identificação dos isolados enterotoxigênicos via PCR. Piracicaba, 2003. 140 p. Tese (Doutorado em Ciências) - Centro de Energia Nuclear na Agricultura, Universidade de São Paulo.

33 CHENG-CHUN, C.; LI-FEN, C. Enterotoxin production by Staphylococcus warneri CCRC 12929, a coagulase-negative strain. Journal of Food Protection, Des Moines, v. 60, n. 8, p. 923-927, Aug. 1997.

$34 \mathrm{COUCH}$, J. L.; SOLTIS, M. T.; BETLEY, M. J. Cloning and nucleotide sequence of the type E staphylococcal enterotoxin gene. Journal of Bacteriology, Washington, v. 170, n. 7, p. 2954-2960, Jul. 1988.

35 CUNHA NETO, A.; SILVA, C. G. M.; STANFORD, T. L. M. Staphylococcus enterotoxigênicos em alimentos in natura e processados no estado de Pernambuco, Brasil. Ciência e Tecnologia de Alimentos, Campinas, v. 22, n. 3, p. 263271, set/dez. 2002.

36 DE BUYSER, M. L. D.; DUFOUR, B.; MAIRE, M.; LAFARGE, V. Implication of milk and milk products in food-borne diseases in France and in different industrialized countries. International Journal of Food Microbiology, Amsterdam, v. 67, n. 1, p. 1-17, Jan. 2001.

37 DE LUCA, G.; ZANETTI, F.; STAMPI, S. Staphylococcus aureus in dairy products in the Bologna area. International Journal of Food Microbiology, Amsterdam, v. 35, n. 3, p. 267-270, Apr. 1997.

38 DINGES, M. M.; ORWIN, P. M.; SCHLIEVERT, P. M. Exotoxins of Staphylococcus aureus. Clinical Microbiology Reviews, Minneapolis, v. 13, n. 1, p. 16-34, Jan. 2000.

39 DODD, C. E. R.; SHARMA, N. K.; REES, C. E. D. Development of a single-reaction multiplex PCR toxin typing assay for Staphylococcus strains. Applied and Environmental Microbiology, Washington, v. 66, n. 4, p. 1347-1353, Apr. 2000. 
40 FEITOSA, T.; BORGES, M. F de; NASSU, R. T; AZEVEDO, E. H. F.; MUNIZ, C. R. Pesquisa de Salmonella sp., Listeria sp. e microrganismos indicadores higiênico-sanitários em queijos produzidos no estado do Rio Grande do Norte. Ciência e Tecnologia de Alimentos, Campinas, v. 23, suplemento, p. 162-165, dez. 2003.

41 FITZGERALD, J. R.; MONDAY, S. R.; FOSTER, T. J.; BOHACH, G. A.; HARTIGAN, P.J.; MEANEY, W.J.; SMYTH, C. J. Characterization of a putative pathogenicity island from bovine Staphylococcus aureus encoding multiple superantigens. Journal of Bacteriology, Washington, v. 183, n. 1, p. 63-70, Jan. 2001

42 FAO/WHO. Food and Agriculture Organization/Wolrd Health Organization. Statistical information on food-borne disease in Europe microbiological and chemical hazards. In: PAN-EUROPEAN CONFERENCE ON FOOD SAFETY AND QUALITY, 1, 2002, Budapest. [Proceeding]. Roma: WHO, 2002. 15p. Disponível em: <ftp://ftp.fao.org/docrep/fao/meeting/004/ y369e/y369e00.pdf>. Acesso em: 17 Jul. 2006.

43 FREITAS, E. I. Detecção de genes de enterotoxinas de Staphylococcus sp. isolados de queijo Minas Frescal. Rio de Janeiro, 2005. 106 p. Dissertação (Mestrado em Vigilância Sanitária) - Instituto Nacional de Controle de Qualidade em Saúde, Fundação Oswaldo Cruz.

44 HILUY, D. J.; ARAÚJO, R. E. S. Avaliação da qualidade microbiológica de queijos de coalho comercializados em Fortaleza - CE. Revista Higiene Alimentar, São Paulo, v. 13, n. 61, p. 28-36, maio/abri. 1999.

45 HOLECKOVÁ, B.; HOLODA, E.; FOTTA, V.; KALINÁCOVÁ, V.; GONDOL, J.; GROLMUS, J. Occurrence of enterotoxigenic Staphylococcus aureus in food. Annals of Agricultural and Environmental Medicine, Dublin, v. 9, n. 3, p. 179182, Mar. 2002.

46 IKEDA, T.; TOMATE, N.; YAMAGUCHI, K.; MAKINO, S. Mass outbreak of food poisoning disease caused by small amounts of Staphylococal enterotoxins A and H. Applied and Environmental Microbiology, Washington, v. 71, n. 5, p. 2793-2795, May 2005.

47 ICMSF. International Commission on Microbiological Specifications for Foods. Staphylococcus aureus. In: ICMSF. Microorganisms in food 5: characterization of microbial pathogens. New York: Kluvers Academic, 1996. v. 5. p. 299-333.

48 INPPAZ/OPS/OMS. Instituto Panamericano de Protección de los Alimentos y Zoonosis / Organización Panamericana de la Salud/Organización Mundial de la Salud. Vigilancia Epidemiológica. Sistema de información regional para la vigilancia epidemiológica de las enfermedades transmitidas por alimentos [SIRVETA]. Disponível em: <http://www.panalimentos.org/sirveta/e/salida2.asp>. Acesso em: 14 Jul. 2006.

49 JABLONSKI, L. M. ; BOHACH, G. A. Staphylococcus aureus. In: DOYLE, M. P.; BEUCHAT, L. R.; MONTVILLE, T. J. (Ed.). Food microbiology, fundamentals and frontiers. $2^{\text {nd }}$ ed. Washington: ASM, 2001. p. 411-434.

50 JARRAUD, S.; COZON, G; VANDERNESCH, F.; BES, M.; ETIENNE, J.; LINA, G. Involvement of enterotoxin G and I in staphylococcal toxic shock syndrome and staphylococcal scarlat fever. Journal of Clinical Microbiology, Washington v. 37, n. 8, p. 2446-2449, Aug. 1999.

51 JARRAUD, S.; PEYRAT, M. A.; LIM, A.; TRISTAN, A.; BES, M.; MOUGEL, C.; ETIENNE, J.; VANDENESCH, F.; BONNEVILLE, M.; LINA, G. Cgc, a highly prevalent operon of enterotoxin gene, forms a putative nursery of superantigens in Staphylococcus aureus. Journal of Immunology, Bethesda, v. 166, n. 1, p. 669-677, Jan. 2001

52 JONES, C. L.; KHAN, S. A. Nucleotide sequence of the enterotoxin B gene from Staphylococcus aureus. Journal of Bacteriology, Washington, v. 166, n. 1, p. 20-33, Apr. 1986.

53 JØRGENSEN, H. J.; MATHISEN, T.; LØVSETH, A.; OMOE, K.; QVALE, S.; LONCAREVIC, S. An outbreak of staphylococcal food poisoning caused by enterotoxin $\mathrm{H}$ in mashed potato made with raw milk. FEMS Microbiology Letters, Amsterdam, v. 252, n. 2, p. 267-272, Feb. 2005.

54 KHAMBATY, F. M.; BENNET, R.W.; SHAH, D. B. Application of pulse field gel electrophoresis to the epidemiological characterization of Staphylococcus intermedius implicated in a food-related outbreak. Epidemiology and Infection, London, v. 113, n. 1, p. 75-81, Jan. 1994.

55 LAMAITA, H. C.; CEROUEIRA, M. M. M. O. P.; CARMO, L. S.; SANTOS, D. A.; PENNA, C. F. A. M.; SOUZA, M. R. Contagem de Staphylococcus sp. e detecção de enterotoxinas estafilocócicas e toxina da síndrome do choque tóxico em amostras de leite cru refrigerado. Arquivos Brasileiros de Medicina Veterinária de Zootecnia, Belo Horizonte, v. 57, n. 5, p. 702-709, maio 2005.

56 LECLERC. V.; DUFOUR, B.; LOMBARD, B.; GAUCHARD, F.; GARIN-BASTUJI, B.; SALVAT, G.; BRISABOIS, A.; POUMEYROL, M.; DE BUYSER, M.L.; GNANOU-BESSE, N.; LAHELLEC, C. Pathogens in meat and milk products: surveillance and impact on human health in France. Livestock Production Science, Paris, v. 76, n. 2, p. 195-202, 2002.

57 LE LOIR, Y.; BARON, F.; GAUTIER, M. Staphylococcus aureus and food poisoning. Genetics and Molecular Research, Ribeirão Preto, v. 2, n. 1, p. 63-76, jan. 2003.

58 LETERTRE, C.; PERELLE, S.; DILASSER, F.; FACH, P. Identification of a new putative enterotoxin SEU encoded by the egc cluster of Staphylococcus aureus. Journal of Applied Microbiology, Belfast, v. 95, n. 1, p. 38-43, Jan. 2003. 
59 LIMA, A. F. Staphylococcus coagulase positiva e enterotoxinas em queijo de coalho. Fortaleza, 2005.86 p. Dissertação (Mestrado em Tecnologia de Alimentos) - Centro de Ciências Agrárias, Universidade Federal do Ceará.

60 MARTIN, S. E.; MYERS, E.R.; LANDOLO, J. J. Staphylococcus aureus. In: HUI, Y.H.; PIERSON, M.D.; GORHAM, J.R. (Ed.). Foodborn disease handbook - bacterial pathogens. $2^{\text {nd }}$ ed. New York: Marcel Dekker, 2001. v. 1. p. $345-381$.

61 MCLAUCHLIN, J.; NARAYANAN, G. L.; MITHANI, V.; O'NEILL, G. The detection of enterotoxin and toxic shock syndrome toxin genes in Staphylococcus aureus by polimerase chain reaction. Journal of Food Protection, Des Moines, v. 63 , n. 4, p. 479-488, Apr. 2000.

62 MEHROTA, M.; WANG, G.; JOHNSON, W.M. Multiplex PCR for detection of genes for Staphylococcus aureus enterotoxins, exfoliative toxins, toxic shock syndrome toxin 1, and methicillin resistance. Journal of Clinical Microbiology, Washington, v. 38, n. 3, p. 1032-1035, Mar. 2000.

63 MENDES, E.S.; LIMA, E.C.; NUMERIANO, A.K.M.; COELHO, M.I.S. Staphylococcus aureus, Salmonella sp. e coliformes em queijos de "coalho" comercializados em Recife. Higiene Alimentar, São Paulo, v. 13, n. 66/67, p. 122-126, nov./ dez. 1999.

64 MEYRAND, A.; VERNOZY-ROZAND, C. Growth and enterotoxin production of Staphylococcus aureus in different cheeses. Revue Medicine Veterinaire, Paris, v. 150, n. 7, p. 601-616, Jul. 1999.

65 MICHINO, H.; OTSUKI, K. Risk factors in causing outbreak of foodborne illness originating in school lunch facilities in Japan. The Journal of Veterinary Medical Science, Tokyo, v. 62, n. 5, 557-560, 2000.

66 MONDAY, S. R.; BONACH, G. A. Use of multiplex PCR to detect classical and newly described pyrogenic toxin in Staphylococcus aureus. Journal of Clinical Microbiology, Washington, v. 37, n. 10, 4311-4314, Oct. 1999.

67 MUNSON, S. H.; TREMAINE, M. T. ; BETLEY, M. J.; WELCH, R. A. Identification and characterization staphylococcal enterotoxins of type $\mathrm{G}$ and from Staphylococcus aureus. Infection and Immunity, Washington, v. 66, n. 7, p. 33373348, Jul. 1998.

68 NIID. National Institute of Infectious Diseases. Staphylococcus food poisoning in Japan. Infectious Agents Surveillance Report, Tokyo, v. 22, n. 8, p. 185-186, 2001.

69 NICOLAU, E. S.; KUAYE, A. Y.; MESQUITA, A. J.; OLIVEIRA, G. R. Avaliação do potencial de produção e tipo de enterotoxinas estafilocócicas encontradas em linhagens de Staphylococcus aureus em extratos de amostras de queijo tipo mussarela fabricado na região de Goiânia - GO. Revista do Instituto de Laticínios Cândido Tostes, Juiz de Fora, v. 56, n. 321, p. 92-101, jul./ago. 2001.

70 NORMANNO, G.; FIRINU, A.; VIRGILIO, S.; MULA, G; DAMBROSIO, A.; POGGIU, A.; DECASLELLI, L.; MIONI, R.; SCUOTA, S.; BALZONI, G.; DI GIANNATALE, E.; SALINETTI, A. P.; LA SALANDRA, G.; BARTOLI, M; ZUCCON, F.; PIRINO, T.; SIAS, S.; PARISI, A.; QUAGLIA, N. C.; CELANO, G. V. Coagulase-positive Staphylococci and Staphylococcus aureus in food products marketed in Italy. International Journal of Food Microbiology, Amsterdam, v. 98, n. 1, p. 73-79, Jan. 2005

71 OLSEN, S. J.; MACKINON, L. C.; GOULGING, J. S.; SLUTSKER, L. Surveillance for foodborne disease outbreaks, 1992-1997. Morbidity and Mortality Weekly Report, Atlanta, v. 49, n. SS01, p. 1-51, Mar. 2000.

72 OMOE, K.; HU, D. L.; TAKAHASHI-OMOE, H.; NAKANE, A.; SHINAGAWA, K. Comprehensive analysis of classical and newly described staphylococcal superantigenic toxin genes in Staphylococcus aureus isolates. FEMS Microbiology Letters, Amsterdam, v. 246, n. 2, p. 191-198, May 2005.

73 OMOE, K.; HU, D.L.; TAKAHASHI-OMOE, H.; NAKANE, A.; SHINAGAWA, K. Identification and characterization of a new staphylococcal enterotoxin- related putative toxin encoded by to kinds of plasmids. Infection and Immunity, Washington, v. 71, n. 6, p. 6088-6094, Jun. 2003.

74 OMOE, K.; ISHIKAWA, M.; YU, S.; HU, D.L.; UEDA, S.; SHINAGAWA, K. Detection of seg, seh, and sei genes in Staphylococcus aureus isolates and determination of the enterotoxin productive of S. aureus isolates harboring seg, seh, or sei genes. Journal of Clinical Microbiology, Washington v. 40, n. 3, p. 857-862, Mar. 2002.

75 OMORI, G.; KATO, Y. A staphylococcal food-poisoning caused by a coagulase-negative strain. Biken's Journal, Berlin, v.2, p. 92- 92, Jan. 1959.

76 ORWIN, P. M.; FITZGERALD, J. R.; LEUNG, D. Y. M.; GUTERREZ, J. A.; BOACH, G. A.; SCHLIEVERT, P. M. Characterization of Staphylococcus aureus enterotoxin L. Infection and Immunity, Washington, v. 71, n. 2, p. 2916-2919, Feb. 2003.

77 ORWIN, P. M.; LEUNG, D. Y. M.; DONAHUE, H. I.; NOVICK, R. P.; SCHLIEVERT, P. M. Biochemical and biological properties of staphylococcal enterotoxin K. Infection and Immunity, Washington, v. 69, n. 3, p. 360-366, Mar. 2001

78 PAIVA. M. S. D.; CARDONHA, A. M. S. Queijo de coalho artesanal e industrializado produzido no Rio Grande do Norte. Revista Higiene Alimentar, São Paulo, v.13, n. 61, p. 33-37, jan./fev. 1999. 
79 PEREIRA, M. L.; CARMO, L. S.; SANTOS, E. J.; PEREIRA, J. L.; BERGDOLL, M. S. Enterotoxin H in staphylococcal food poisoning. Journal of Food Protection, Des Moines, v.59, n. 5, p. 559-561, May 1996.

80 PERSI, J. T. M. Queijo Minas tipo frescal artesanal e industrial: qualidade microscópica, microbiológica e teste de sensibilidade aos agentes antimicrobianos. Revista Higiene Alimentar, São Paulo, v. 15, n. 83, p.63-70, abr. 2001.

81 PIMBLEY, D. W.; PATEL, P. D. A review of analytical methods for the detection of bacterial toxins, Journal of Applied Microbiology Symposium Supplement, London, v. 84, n. S1, p. 98S-109S, Jul. 1998.

82 RAPINI, L. S.; FEIJÓ, L. D.; VERAS, J. F.; NASCIMENTO, K. F.; AMADO, J. B.; COUTO, I. P.; CARMO, L. S.; SILVA, M. C. C.; CERQUIRA, M. M. O. P. Pesquisa de Salmonella sp., Escherichia coli, Listeria sp. e Staphylococcus sp. e detecção de enterotoxinas estafilocócicas em queijo tipo coalho. Revista do Instituto de Laticínios Cândido Tostes, Juiz de Fora, v. 57, n. 327, p. 60-65, jul./ago. 2002.

83 REISER, R. F.; ROBBINS, R.N.; NOLETO, A. L.; KHOE, G.P.; BERGDOLL, M. S. Identification, purification, and some physicochemical properties of staphylococcal enterotoxin $\mathrm{C}_{3}$. Infection and Immunity, Washington, v. $45, \mathrm{n}$. 3 , p. $625-630$, Sept. 1984

84 REN, K.; BANNAN, J. D.; PANCHOLI, V.; CHEUNG, A. L.; ROBBINS, J. C.; FISCHETTI, V. A.; ZABRISKIE, J. B. Characterization and biological properties of a new staphylococcal enterotoxin. The Journal Experimental of Medicine, New York, v. 180, n. 5 , p. 1675-1683, Nov. 1994

85 RODRIGUEZ, L.; NUNEZ, F.; CORDOBA, J. J.; BERMUDEZ, E.; ASNSIO, M. A. Gram-positive, catalase cocci from dry cured Iberian ham and their enterotoxigenic potential. Applied and Environmental Microbiology, Washington, v. 62 , n. 6 , p. 1897-1902, Jun. 1996.

86 ROSEC, J. P.; GUIRAUD, O. Staphylococcal enterotoxin genes of classical and new types detected by PCR in France. International Journal of Food Microbiology, Amsterdam, v. 77, n. 1/2, p. 61-70, Jan./Feb. 2002

87 ROSEC, J. P.; GUIRAUD, J. P.; DALET, C.; RICHARD, N. Enterotoxin production by staphylococci isolated from foods in France. International Journal of Food Microbiology, Amsterdam, v. 35, n. 3, p. 213-221, Mar. 1997.

88 SABIONI, J. G.; HIROOKA, E. L.; SOUZA, M. L. R. Intoxicação alimentar por queijo "Minas" contaminado com Staphylococcus aureus. Revista da Saúde Pública, São Paulo, v. 22, n. 5, p. 458-461, 1988.

89 SABIONI, J. G.; NASCIMENTO, D.; PEREIRA, J. L. Intoxicação estafilocócica causada por queijo tipo "Minas" em Ouro Preto, Minas Gerais, 1992. Revista Higiene Alimentar, São Paulo, v. 8, n. 33, p. 22-23, jan. 1994.

90 SENA, M. J. Perfil epidemiológico, resistência a antibióticos e aos conservantes nisina e sistema lactoperoxidase de Staphylococcus sp. isolados de queijos de coalho comercializados em Recife-PE. Belo Horizonte, 2000. 75 p. Tese (Doutorado em Veterinária) - Faculdade de veterinária, Universidade Federal de Minas Gerais.

91 SORIANO, J. M.; FRONT, G.; MOLTÓ, J. C.; MAÑES, J. Enterotoxigenic staphylococci and their toxins in restaurant foods. Trends in Food Science and Technology, Cambridge, v. 13, n. 2, p. 60-67, Feb. 2002.

92 SU, Y. C.; WONG, A. C. L. Identification and purification of a new staphylococcal enterotoxin, H. Applied and Environmental Microbiology, Washington, v. 61, n. 4, p. 1438-1443, Apr. 1995.

93 USDA. United States Department of Agriculture. Economic Research Service. Economics of foodborne disease: food and pathogens. Disponível em: <http://www.ers.usda.gov/Briefing/FoodboeneDisease/foodandpathogens.htm>. Acesso em: 12 maio 2006.

94 VALLE, J.; GOMEZ-LUCIA, E.; PIRIZ, S.; GOYACHE, J.; ORDEN, J. A.; VADILLO, S. Enterotoxin production by staphylococci isolated from healthy goats. Applied and Environmental Microbiology, Washington, v. 56, n. 5, p.1323-1326, May 1990

95 VERAS, J. F.; SANTOS, D. A.; CARMO, L. S.; FERNANDES, T. M. G.; AZALIM, C. C.; SILVA, M. C. C.; MARTINS, R. T.; CERQUEIRA, M. M.O.P. Levantamento de surtos de toxinfecção alimentar envolvendo leite e produtos derivados no estado de Minas Gerais. Revista Higiene Alimentar, São Paulo, v.17, n. 104/105, p. 218-119, jan./fev. 2003.

96 VERNOZY-ROZAND, C.; MAZUY, C.; PERRIN, G.; HAOND, F.; BES, M.; BRUN, Y.; FLEURETTE, J. Identification Micrococcaceae isolated from goat's milk and cheese in the Poitou-Charentes region. International Journal of Food Microbiology, Amsterdam, v. 30, n. 3, p. 373-378, Mar. 1996a.

97 VERNOZY-ROZAND, C.; MAZUY, C.; PREVOST, G.; LAPEYRE, C.; BES, M.; BRUN, Y.; FLEURETTE, J. Enterotoxin production by coagulase-negative staphylococcal isolated from goats and cheese. International Journal of Food Microbiology, Amsterdam, v. 30, n. 3, p. 271-280, Mar. 1996b.

98 YARWOOD, J. M.; MCCORMICK, J. K.; PAUSTIAN, M. L.; ORWIN, P. M.; KAPUR, V.; SCHLIEVERT, P. M. Characterization and expression analysis of Staphylococcus aureus pathogenicity Island 3: implications for the evolution of staphylococcal pathogenicity islands. Journal Biological Chemistry, v. 277, n. 15, p. 13138-13147, Apr. 2002. 
99 ZHANG, S.; IANDOLO, J. J.; STEWART, G. C. The enterotoxin D plasmid of Staphylococcus aureus encodes a second enterotoxin determinant (sej). FEMS Microbiology Letters, Amsterdam, v. 168, n. 2, p. 227 -233, Nov. 1998. 